NOTES

\title{
Effects of Trifluoromethyl Side Groups on Gas Permeability and Permselectivity in Polyimides
}

\author{
Kazuhiro TanaKa, Masaaki OKano, Hidetoshi Kita, \\ Ken-ichi Oкамото, and Shiro NisHI
Department of Advanced Materials Science and Engineering, Faculty of Engineering,
Yamaguchi University, Ube, Yamaguchi 755, Japan
*NTT Interdisciplinary Research Laboratories, 3-9-11, Midori-cho, Musashino-shi, Tokyo 180, Japan

(Received November 15, 1993)

\author{
KEY WORDS Gas Permeability / Permselectivity / Polyimides / Trifluoro- \\ methyl Side Groups / Gas Separation /
}

Polyimides are interesting in application for gas separation membranes. The relationship between chemical structure and gas permeability has been extensively investigated. ${ }^{1-6}$ In general, polymeric membranes with higher permeability tend to exhibit lower permselectivity. However, the introduction of hexafluoroisopropylidene $-\mathrm{C}\left(\mathrm{CF}_{3}\right)_{2}-$ linkage in polymer chain of polyimide increases gas permeability without significant loss of permselectivity for $\mathrm{CO}_{2} / \mathrm{CH}_{4}$ separation. ${ }^{1,4,5}$ The polyimide prepared from 4,4'-hexafluoroisopropylidene phthalic anhydride (6FDA) and 2,2'-bis(aminophenyl)hexafluoropropane (BAHF), which has two $-\mathrm{C}\left(\mathrm{CF}_{3}\right)_{2}$ - linkages in the repeat unit, is excellent for $\mathrm{CO}_{2} / \mathrm{CH}_{4}$ separation. $^{5}$

The $\mathrm{CF}_{3}$ groups in the $-\mathrm{C}\left(\mathrm{CF}_{3}\right)_{2}-$ linkages cause less-efficient packing of polymer chains due to reduced molecular interaction and steric hindrance. Reduction of the chain packing increases diffusion coefficients of gases and decreases the diffusivity selectivity. Simultaneously, the $\mathrm{CF}_{3}$ groups restrict internal rotation of the phenylene rings adjacent to the linkages and reduce local mobility of the polymer chain. In the glassy state, restriction of the local motion of polymer chains tends to reduce diffusion coefficients of gases and increase the diffusivity selectivity. Thus, $\mathrm{CF}_{\mathbf{3}}$ groups have two opposite effects. In general, the former effect is larger than the latter. Therefore, for the gas separation system such as $\mathrm{H}_{2} / \mathrm{CH}_{4}$, where there is a large difference in molecular size between the gas pair (effective diameter: $0.29 \mathrm{~nm}$ for $\mathrm{H}_{2}, 0.38 \mathrm{~nm}$ for $\mathrm{CH}_{4}$ ), the introduction of $-\mathrm{C}\left(\mathrm{CF}_{3}\right)_{2}-$ linkage causes considerable increase in diffusion coefficients with a large decrease in the diffusivity selectivity. For the $\mathrm{CO}_{2} / \mathrm{CH}_{4}$ system, where there is small difference in molecular size (effective diameter: $0.35 \mathrm{~nm}$ for $\mathrm{CO}_{2}$ ) and large difference in molecular shape between the gas pair, the former effect on diffusivity selectivity is rather small because of the small difference in molecular size and is canceled out by the latter effect. This is the reason that the introduction of $-\mathrm{C}\left(\mathrm{CF}_{3}\right)_{2}-$ linkage causes a large increase in permeability without a significant loss of permselectivity for the $\mathrm{CO}_{2} / \mathrm{CH}_{4}$ separation.

In this study, polyimides with trifluoromethyl side groups $\left(\mathrm{CF}_{3}\right)$ on phenylene rings in polymer chain were prepared, and permeation properties of $\mathrm{H}_{2}, \mathrm{CO}, \mathrm{CO}_{2}$, and $\mathrm{CH}_{4}$ were measured to investigate the effects of the $\mathrm{CF}_{3}$ side groups on the gas permeability and 
permselectivity.

\section{EXPERIMENTAL}

A diamine used was 2,2'-bis(trifluoromethyl)4,4'-diaminobiphenyl (TFDB). Tetracarboxylic dianhydrides used were 1-(trifluoromethyl)2,3,5,6-benzenetetracarboxylic dianhydride (P3FDA), pyromellitic dianhydride (PMDA), and 6FDA. The chemical structures of polyimides prepared are shown in Figure 1 together with those of related polyimides. Polymerization and film preparation of the polyimides were described in previous papers. ${ }^{7,8}$ The films used were $20-30 \mu \mathrm{m}$ thick. The characterization experiments were carried out by methods described elsewhere. ${ }^{3}$ A vacuum time-lag method was used to measure permeability coefficient $P$. A Sartorius S3D-P model electronic microbalance was used to measure the solubility coefficient $S$. $P$ and $S$ were measured at $10 \mathrm{~atm}$ and $35^{\circ} \mathrm{C}$. Average diffusion coefficient $\bar{D}$ was evaluated by equation $\bar{D}=P / S$.

\section{RESULTS AND DISCUSSION}

Characterization results of the polyimides are listed in Table I together with those of the related polyimides from $\mathrm{BAHF},{ }^{5} 2,2^{\prime}, 4,4^{\prime}$ tetramethyldiaminobenzidine (TMBZ), ${ }^{9}$ and $4,4^{\prime}$-oxydianiline ( $\left.p p^{\prime} \mathrm{ODA}\right) .{ }^{5}$ Fraction of "free space" $V_{\mathrm{F}}$ refers to the ratio of the so-called "expansion volume" 10 to the observed volume and were calculated from eq 1

$$
V_{\mathrm{F}}=\left(V_{\mathrm{T}}-V_{0}\right) / V_{\mathrm{T}}
$$

where $V_{\mathrm{T}}$ and $V_{0}$ are specific molar volumes at temperature $T$ and $0 \mathrm{~K}$, respectively. $V_{\mathrm{T}}$ was<smiles>[R2]N1C(=O)N([CH2-])C1=O</smiles>

- $\mathrm{R}_{1}^{\prime}$, anhydride
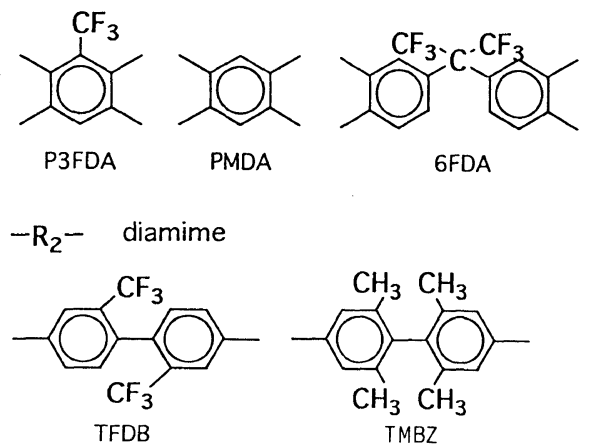

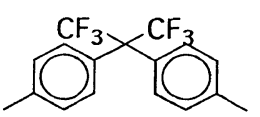

BAHF

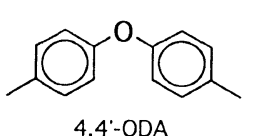

4, $4^{\circ}$-ODA
Figure 1. Chemical structures of polyimides.

Table I. Characterization of polyimide films $\mathrm{s}^{\mathrm{a}}$

\begin{tabular}{|c|c|c|c|c|c|}
\hline Polyimides & $\frac{T_{\mathrm{g}}}{{ }^{\circ} \mathrm{C}}$ & $\frac{\text { Density }}{\mathrm{g} \mathrm{cm}^{-3}}$ & $\frac{V_{F}}{(-)}$ & $\frac{\delta}{\left(\mathrm{J} \mathrm{cm}^{-3}\right)^{1 / 2}}$ & {$[\mathrm{~F}]$} \\
\hline 6FDA-TFDB & 335 & 1.477 & 0.190 & 24.6 & 24 \\
\hline $6 \mathrm{FDA}-\mathrm{TMBZ} \mathrm{b}^{\mathrm{b}}$ & 346 & 1.355 & 0.146 & 25.9 & 13 \\
\hline $6 \mathrm{FDA}-\mathrm{BAHF} \mathrm{F}^{\mathrm{c}}$ & 305 & 1.480 & 0.182 & 24.1 & 24 \\
\hline $6 \mathrm{FDA}-p p^{\prime} \mathrm{ODA}{ }^{\mathrm{c}}$ & 299 & 1.432 & 0.165 & 27.2 & 14 \\
\hline PMDA-TFDB & $>400$ & 1.489 & 0.160 & 28.7 & 18 \\
\hline $\mathrm{PMDA}^{-} p p^{\prime} \mathrm{ODA}{ }^{\mathrm{c}}$ & $(420)$ & 1.395 & 0.129 & 34.6 & 0 \\
\hline P3FDA-TFDB & 322 & 1.590 & 0.142 & 26.8 & 25 \\
\hline
\end{tabular}

a $[\mathrm{F}]$ is the fluorine content, in $\left[10^{-3} \mathrm{~mol} \mathrm{~cm}^{-3}\right]$.

b Reference 9.

c Reference 5 . 
Table II. Permeability, diffusion and solubility coefficients and ratios of coefficients for $\mathrm{CO}_{2} / \mathrm{CH}_{4}$ system in polyimides at $35^{\circ} \mathrm{C}$ and $10 \mathrm{~atm}^{\mathrm{a}}$

\begin{tabular}{|c|c|c|c|c|c|c|c|c|c|}
\hline Polyimides & $P_{\mathrm{CO}_{2}}$ & $\bar{D}_{\mathrm{CO}_{2}}$ & $S_{\mathrm{CO}_{2}}$ & $P_{\mathrm{CH}_{4}}$ & $\bar{D}_{\mathrm{CH}_{4}}$ & $S_{\mathrm{CH}_{4}}$ & $P_{\mathrm{CO}_{2}} / P_{\mathrm{CH}_{4}}$ & $\bar{D}_{\mathrm{Co}_{2}} / \bar{D}_{\mathrm{CH}_{4}}$ & $S_{\mathrm{CO}_{2}} / S_{\mathrm{CH}_{4}}$ \\
\hline 6FDA-TFDB & 56 & 11 & 5.3 & 1.7 & 1.1 & 1.6 & 34 & 10 & 3.4 \\
\hline 6FDA-TMBZ & 50 & - & - & 1.4 & - & - & 35 & - & - \\
\hline 6FDA-BAHF ${ }^{c}$ & 51 & 8.1 & 6.3 & 1.3 & 0.66 & 2.0 & 38 & 12 & 3.1 \\
\hline $6 \mathrm{FDA}-p p^{\prime} \mathrm{ODA}^{\mathrm{c}}$ & 17 & 3.1 & 5.4 & 0.34 & 0.22 & 1.6 & 49 & 14 & 3.4 \\
\hline PMDA-TFDB & 14 & 3.2 & 4.4 & 0.37 & 0.30 & 1.3 & 37 & 11 & 3.5 \\
\hline $\mathrm{PMDA}^{-} p p^{\prime} \mathrm{ODA}^{\mathrm{c}}$ & 3.6 & 0.80 & 4.5 & 0.094 & 0.079 & 1.2 & 38 & 10 & 3.8 \\
\hline P3FDA-TFDB & 1.7 & 0.66 & 2.6 & 0.022 & 0.034 & 0.69 & 76 & 19 & 3.9 \\
\hline
\end{tabular}

a $P$ is in $10^{-10} \mathrm{~cm}^{3}$ (STP) $\mathrm{cm}^{-1} \mathrm{~s}^{-1} \mathrm{cmHg}^{-1}, \bar{D}$ is in $\mathrm{cm}^{2} \mathrm{~s}^{-1}$, and $S$ is in $10^{-2} \mathrm{~cm}^{3}$ (STP) $\mathrm{cm}^{-3} \mathrm{cmHg}^{-1}$.

b Reference 9.

c Reference 5 .

calculated from density data, $V_{0}$ was estimated to be 1.3 times $^{11}$ the van der Waals volume calculated by the group-contribution method of Bondi. ${ }^{12}$ The solubility parameter $\delta$ was calculated by the group-contribution method of van Krevelen. ${ }^{11}$

Permeation data for the $\mathrm{CO}_{2} / \mathrm{CH}_{4}$ system are listed in Table II. $\bar{D}$ varied by a factor of 30 , while $S$ varied by a factor of 2 with changing the chemical structure. The differences in $P_{\mathrm{CO}_{2}}$ and $P_{\mathrm{CO}_{2}} / P_{\mathrm{CH}_{4}}$ were mainly attributed to

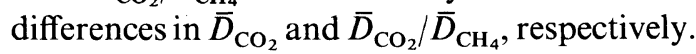
$S_{\mathrm{CO}_{2}} / S_{\mathrm{CH}_{4}}$ was almost constant around 3.5. Permeation data for the $\mathrm{H}_{2} / \mathrm{CO}$ and $\mathrm{H}_{2} / \mathrm{CH}_{4}$ systems are listed in Table III. For these systems, differences in $P$ and $P$ ratios are considered due to those in the $\bar{D}$ and $\bar{D}$ ratios, respectively.

The permeability and permselectivity for 6FDA-TFDB polyimide were similar with those for 6FDA-BAHF. The $\mathrm{CF}_{3}$ groups in TFDB moiety which cause less-efficient packing of polymer chains seem to result in high permeability. Molecular model examination using a Stuart type model showed that two $\mathrm{CF}_{3}$ side groups on ortho positions to the single bond of biphenyl in TFDB moiety restrict the internal rotation of biphenyl by the steric hindrance and reduce local motion of the polymer chains. This situation was similar to that for $-\mathrm{C}\left(\mathrm{CF}_{3}\right)_{2}-$ linkage mentioned above. It is noted that the permeability and perm-
Table III. Permeability coefficients and permeability coefficient ratios for $\mathrm{H}_{2} / \mathrm{CO}, \mathrm{H}_{2} / \mathrm{CH}_{4}$ systems in polyimides at $35^{\circ} \mathrm{C}$ and $10 \mathrm{~atm}^{\mathrm{a}}$

\begin{tabular}{|c|c|c|c|}
\hline Polyimides & $P_{\mathrm{H}_{2}}$ & $P_{\mathrm{H}_{2}} / P_{\mathrm{CO}}$ & $P_{\mathrm{H}_{2}} / P_{\mathrm{CH}_{4}}$ \\
\hline 6FDA-TFDB & 120 & 26 & 73 \\
\hline 6FDA-TMBZ ${ }^{\mathrm{b}}$ & 100 & - & 75 \\
\hline 6FDA-BAHF & 108 & 26 & 81 \\
\hline $6 \mathrm{FDA}-p p^{\prime} \mathrm{ODA}^{\mathrm{c}}$ & 41 & 35 & 120 \\
\hline PMDA-TFDB & 34 & 33 & 90 \\
\hline $\mathrm{PMDA}-p p^{\prime} \mathrm{ODA}{ }^{\mathrm{c}}$ & 11 & 39 & 110 \\
\hline P3FDA-TFDB & 8.5 & 66 & 380 \\
\hline
\end{tabular}

a $P$ is in $10^{-10} \mathrm{~cm}^{3}$ (STP) $\mathrm{cm}^{-1} \mathrm{~s}^{-1} \mathrm{cmHg}^{-1}$.

b Reference 9 .

c Reference 5 .

selectivity of 6FDA-TMBZ polyimide are also similar with those of 6FDA-TFDB and 6FDA-BAHF polyimides. This indicates that the four $\mathrm{CH}_{3}$ groups on ortho positions to single bond of biphenyl and two $\mathrm{CF}_{3}$ groups have similar effects on the restriction of both efficient polymer chain packing and internal rotation of biphenyl.

In spite of higher content of fluorine, P3FDA-TFDB polyimide had smaller $V_{F}$, lower $P$ as compared with PMDA-TFDB. This indicates that $\mathrm{CF}_{3}$ substitution of benzene ring in PMDA moiety causes efficient packing of the polymer chains and results in reductions in both $P$ and $\bar{D}$. These variations are contrary to the above-mentioned effects of the $\mathrm{CF}_{3}$ groups in the $-\mathrm{C}\left(\mathrm{CF}_{3}\right)_{2}$-linkage. The reason is 
considered to be as follows. Charge transfer (CT) interaction takes an important part in polymer chain-chain interactions in aromatic polyimides. ${ }^{13}$ The magnitude of CT interaction depends on the electron affinity of the acid dianhydride moiety and electron ionization potential of the diamine moiety. The color of the polyimide films is attributed mainly to CT absorption. ${ }^{14}$ The P3FDA-TFDB polyimide films are yellow, whereas PMDA-TFDB and 6FDA-TFDB polyimide films are pale yellow and colorless, respectively. In the electronic absorption spectra of the films $(20 \mu \mathrm{m}$ thick), absorbance of 0.3 was observed at 470, 425, $375 \mathrm{~nm}$ for P3FDA, PMDA, and 6FDA. This indicates that the magnitude of $\mathrm{CT}$ interaction is in the order P3FDATFDB $>$ PMDA-TFDB $>6$ FDA-TFDB. The $-\mathrm{C}\left(\mathrm{CF}_{3}\right)_{2}-$ groups in $6 \mathrm{FDA}$ and $\mathrm{BAHF}$ reduce electron-accepting and electron-donating ability of the moiety, respectively by interuption of the $\pi$-electron conjugation, resulting in significant reduction in $\mathrm{CT}$ interaction. As a result, 6FDA- and/or BAHF-based polyimide films are less-colored. The reduced molecular interaction is one reason why polyimides having $-\mathrm{C}\left(\mathrm{CF}_{3}\right)_{2}-$ groups have large $V_{\mathrm{F}}$. The introduction of an electron-attracting substituent such as $\mathrm{CF}_{3}$ on the benzene ring in the diamine increases the ionization potential and therefore reduces $\mathrm{CT}$ interaction. The introduction of electron-attracting substituents into the dianhydride increases the electron affinity and therefore enhances CT interaction. The stronger molecular interactions of polymer chains in P3FDA-TFDB polyimide result in smaller $V_{\mathrm{F}}$ and lower $P$ and $\bar{D}$, compared with PMDA-TFDB polyimide.

There is a general trend for every gas separation system that polymers having higher
$P$ exhibit lower $P$ ratios. Robeson reported an upper bound line for membrane performance of polymers in the plots of logarithm of $P$ ratio for each gas pair versus logarithm of $P$ of the more permeable gas. ${ }^{15}$ The plots for $6 \mathrm{FDA}$ TFDB, 6FDA-TMBZ, and 6FDA-BAHF polyimides for $\mathrm{H}_{2} / \mathrm{CH}_{4}$ and $\mathrm{CO}_{2} / \mathrm{CH}_{4}$ systems were on upper bound lines. The plot for P3FDA-TFDB polyimide for $\mathrm{H}_{2} / \mathrm{CH}_{4}$ system was slightly below the upper bound line.

\section{REFERENCES}

1. T. H. Kim, W. J. Koros, and G. R. Husk, Sep. Sci. Technol., 23, 1611 (1988).

2. S. A. Stern, Y. Mi, and H. Yamamoto, J. Polym. Sci., Polym. Phys. Ed., 27, 1887 (1989).

3. K. Tanaka, H. Kita, K. Okamoto, A. Nakamura, and Y. Kusuki, J. Membrane Sci., 47, 203 (1989).

4. M. R. Coleman and W. J. Koros, J. Membrane Sci., 50, 285 (1990).

5. K. Tanaka, H. Kita, and K. Okamoto, Polymer, 33, 585 (1992).

6. K. Tanaka, M. Okano, H. Toshino, H. Kita, and K. Okamoto, J. Polym. Sci., Polym. Phys. Ed., 30, 907 (1992).

7. T. Matsuura, Y. Hasuda, S. Nishi, and N. Yamada, Macromolecules, 24, 5001 (1991).

8. T. Matsuura, M. Ishizawa, Y. Hasuda, and S. Nishi, Macromolecules, 25, 3540 (1991).

9. T. Kasai, Y. Sakata, H. Takeuchi, and Y. Kobayashi, Mitsubishi Kasei R\&D Review, 6, 77 (1992).

10. R. N. Haward, J. Macromol. Sci., Rev. Macromol. Chem., C4, 191 (1970).

11. D. W. Van Krevelen, "Properties of Polymers," Elsevier, Amsterdam, 1976.

12. A. Bondi, J. Phys. Chem., 68, 441 (1964); A. Bondi, "Physical Properties of Molecular Crystals, Liquids, and Gases," John Wiley \& Sons, New York, N.Y., 1968.

13. T. L. St. Clair, "Polyimide," D. Wilson, H. D. Stenzenberger, and P. M. Hergenrother, Ed., Chapman and Hall, New York, N.Y., 1990, p 58.

14. A. K. St. Clair, T. L. St. Clair, and K. I. Shevket, Polym. Mater. Sci. Eng., 51, 62 (1984).

15. L. M. Robeson, J. Membrane Sci., 62, 165 (1991). 